\title{
Kinin-generating cellular model obtained from human glioblastoma cell line U-373*
}

\author{
Ibeth Guevara-Lora1凶${ }^{\bowtie}$, Beata Blonska¹, Alexander Faussner² and Andrzej Kozik \\ 1Department of Analytical Biochemistry, Faculty of Biochemistry, Biophysics and Biotechnology, Jagiellonian University, Kraków, Poland; 2Institut \\ für Prophylaxe und Epidemiologie der Kreislaufkrankheiten, Ludwig-Maximilians-University, Munich, Germany.
}

\begin{abstract}
Kinins, a group of important pro-inflammatory peptides, are abundantly found in tissues and biological fluids of cancer patients. Bradykinin, the major representative of kinins, induces vascular permeability and, in consequence, promotes tumor expansion. Additionally, the kinin-induced inflammatory responses, especially those mediated by kinin metabolites without the C-terminal arginine residue, lead to enhanced tumor growth. The present study aimed at analyzing the ability of the human glioblastoma cell line U-373, derived from a malignant tumor, to produce kinin peptides. The proteins involved in kinin generation, i.e., the kininogens and the kallikreins, were shown to be expressed in these cells. Moreover, tumor necrosis factor $a$, a proinflammatory cytokine that mediates tumorigenesis, was found to enhance the expression of enzymes associated with kinin production. The strong binding of kininogen to the cell surface and the enzymatic degradation of this protein by cells suggest the activation of kinin-generating systems. Indeed, glioblastoma cells, pre-treated with tumor necrosis factor $a$, released kinin peptides from exogenous kininogen. The expression of kinin receptors in these cells was also shown to increase under the influence of this cytokine. Our results suggest that the human glioblastoma cell line U-373 constitutes a good cellular model that can be helpful in cancer research focused on kinininduced inflammation. Furthermore, our findings can contribute to new approaches in cancer treatment with the use of kinin receptor antagonists and inhibitors of kinin production.
\end{abstract}

Key words: kinins, bradykinin receptors, cancer, inflammation

Received: 19 April, 2013; accepted: 30 May, 2013; available on-line: 12 June, 2013

\section{INTRODUCTION}

Oncogenic transformation can be initiated and promoted by inflammatory processes leading to tumor appearance and malignant progression (Finger \& Giaccia, 2010). Chronic inflammation and infections are central players in cancer. Besides, enhanced secretion of proinflammatory mediators such as interleukins, interferons, tumor necrosis factor- $\alpha(\mathrm{TNF}-\alpha)$ and tumor growth factor- $\beta$ results in increased angiogenesis, leukocyte recruitment and cell proliferation (Geiger \& Pepper, 2009; Lee et al., 2013). Moreover, some cytotoxic factors, such as proteases, cause cell detachment from the primary tumor with subsequent malignant cell extravasation leading to the metastatic state (Geiger \& Pepper, 2009).
The kinins, universal pro-inflammatory mediators, are also involved in cancer development. These peptides were abundantly detected in tissues and biological fluids of cancer patients (Maeda et al., 1999). Bradykinin $(\mathrm{BK})$, the major representative of this group, induces vascular permeability and, in consequence, promotes tumor expansion. Two primary kinins, BK and kallidin (KD) are produced by serine proteases, the kallikreins, from two precursor proteins, high molecular weight kininogen $(\mathrm{HK})$ and low molecular weight kininogen (LK) (Bhoola et al., 1992; Colman \& Schmaier, 1996; Blais et al., 2000). In tissues, $\mathrm{KD}$ is produced by the action of tissue kallikrein (hK1) on LK. In plasma, $\mathrm{BK}$ is formed from $\mathrm{HK}$ by plasma kallikrein within a multiprotein complex assembled on the surfaces of endothelium and blood cells via specific cell-membrane proteins (Joseph \& Kaplan, 2005). This pathway of HK degradation and $\mathrm{BK}$ release is called the contact system activation. During the generation of kinins on the cell surfaces, some surface-bound proteases, such as factor XII or prolylcarboxypeptidase (PRCP) are involved in the activation of the plasma kallikrein zymogen, prekallikrein (PPK). Kinin concentration in extracellular fluids is controlled by specific peptidases, the kininases, that degrade kinins to shorter peptides (Bhoola et al., 1992; Blais et al., 2000). Most of kinin metabolites are biologically inactive; however, some kininases of the carboxypeptidase class such as carboxypeptidase M (CPM) specifically remove only the C-terminal arginine residue of kinins, giving rise to strongly pro-inflammatory peptides referred to as "des-Arg kinins". The kinins and des-Arg kinins interact with two subtypes of cellular receptors, B1R and B2R, which belong to the G proteincoupled receptor family. The full-length kinins are agonists of B2R whereas des-Arg kinins bind specifically to B1R (Leeb-Lundberg et al., 2005). The kinin-mediated inflammatory responses, especially those induced by des-Arg kinins lead, to enhanced tumor growth (LeebLundberg et al., 2005). Recently, a novel approach based on the use of kinin receptor antagonists as anticancer drugs has been suggested for cancer treatment

\footnotetext{
e-mail: ibeth.quevara-lora@uj.edu.pl
}

* Presented at 40th Jubilee Winter School of the Faculty of Biochemistry, Biophysics and Biotechnology of the Jagiellonian University "Contemporary insights into cancer. Risk, perspectives, expectations", February 16-21, 2013, Zakopane, Poland.

Abbreviations: $B 1 \mathrm{R}$, kinin receptor type $1 ; \mathrm{B} 2 \mathrm{R}$, kinin receptor type 2; BK, bradykinin; CPM, carboxypeptidase M; DAA, dansyl-Ala-Arg$\mathrm{OH}$; DAKD, des-Arg ${ }^{10}$ kallidin; eEF2K, elongation factor 2; FI-HK, fluorescein-labelled kininogen; HK, high molecular weight kininogen; hK1, human tissue kallikrein; KD, kallidin; LK, low molecular weight kininogen; MGTA, 2-mercaptomethyl-3-guanidinoethyl thiopropanoic acid; PPK, human plasma prekallikrein; PRCP, prolylcarboxypeptidase; TNF-a, tumor necrosis factor $a$. 
(Figueroa et al., 2012). Furthermore, a BK analog, Cereport, was introduced to increase the levels of chemotherapeutic agents in brain tumor and the surrounding tissue through the enhancement of permeability of the blood-brain tumor barrier (Dean et al., 1999). However, the authors emphasized the use of this B2R agonist as an adjunctive therapy. Increased permeability can also lead to cell migration and contributes to the invasion of glioblastoma, as has recently been shown by several research groups (Liu at al., 2010; López-Valdés et al., 2010; Montana et al., 2011).

While the presence of kinin-like peptides in tumors is indisputable, the mechanisms of kinin production by tumor cells are poorly recognized. This study aimed at analyzing the ability of the human glioblastoma cell line U-373, derived from a malignant tumor, to produce kinins and des-Arg kinins from exogenous kininogens, especially after cytokine stimulation. In addition, the effect of TNF- $\alpha$ stimulation on the expression of kinin receptors by these cells was also determined.

\section{MATERIALS AND METHODS}

Chemicals. Des-Arg ${ }^{10}$-kallidin (DAKD), dansylAla-Arg-OH (DAA) and KD were supplied by Bachem (Germany). TNF- $\alpha$ was obtained from BD Sciences (Germany) and 2-mercaptomethyl-3-guanidinoethyl thiopropanoic acid (MGTA) from Calbiochem (USA). Antibiotics, antimycotics, cell culture media, fetal bovine serum, non-essential amino acids and sodium pyruvate were purchased from Cytogen (Austria). HK was obtained from Enzyme Research Laboratories (USA), captopril and 1,10-phenantroline from Fluka Analytical (Switzerland) and Fluorescein-Ex Protein Labeling kit from Molecular Probes (USA). $\left[{ }^{3} \mathrm{H}\right]-D A K D$ with a specific radioactivity of $88 \mathrm{Ci} /$ mmol and the Ultima Gold ${ }^{\mathrm{TM}}$ scintillation fluid were obtained from Perkin Elmer (USA). Bacitracin, Fast $\mathrm{BCIP} / \mathrm{NBT}$, tetracycline and other standard chemicals were purchased from Sigma (USA).

Mouse antihuman antibodies against a sequence encompassing amino acids 19-64 (within the HK heavy chain) and against a sequence encompassing amino acids 438-531 (within the HK light chain) and goat antimouse IgG conjugate with alkaline phosphatase were supplied by Santa Cruz (USA).

Cell culture. The human glioblastoma cell line U-373 supplied by ECACC (UK) was cultured in MEM medium supplemented with non essential amino acids, 1 $\mathrm{mM}$ sodium pyruvate, $10 \%$ fetal bovine serum, $1 \mathrm{U} / \mathrm{ml}$ penicillin, $0.1 \mathrm{mg} / \mathrm{ml}$ streptomycin and $2.5 \mu \mathrm{g} / \mathrm{ml} \mathrm{am-}$

Table 1. Sequences of primers used for RT-PCR analysis.

\begin{tabular}{|c|c|c|}
\hline Gene & Forward primer & Reverse primer \\
\hline BR1 & $5^{\prime}$ gcccaagacaaacaccagatc $3^{\prime}$ & $5^{\prime}$ gcaactgaacgtggcagaa $3^{\prime}$ \\
\hline BR2 & $5^{\prime}$ gtgcccatgccgcttgctcc $3^{\prime}$ & $5^{\prime}$ tcggcgctgaaagaggccgt $3^{\prime}$ \\
\hline CPM & $5^{\prime}$ gcctgatgatgatgtttttc $3^{\prime}$ & $5^{\prime}$ tggtgatgtgggttgagttt $3^{\prime}$ \\
\hline eEF-2K & $5^{\prime}$ gacatcaccaagggtgtgcag $3^{\prime}$ & $5^{\prime}$ gcggtcagcacactggcata $3^{\prime}$ \\
\hline hK1 & $5^{\prime}$ gctcattgcatcagcgacaattacc $3^{\prime}$ & $5^{\prime}$ ctgcttggcgggtgtggttct $3^{\prime}$ \\
\hline PPK & $5^{\prime}$ tgggtaaccggatggggcttct $3^{\prime}$ & $5^{\prime}$ agcacagaccatccgttgggtt $3^{\prime}$ \\
\hline Kininogen & $5^{\prime}$ gcaagagtacaggtggtggctggca $3^{\prime}$ & $5^{\prime}$ cctggaggccttttcatcagtgaga $3^{\prime}$ \\
\hline PRCP & $5^{\prime}$ acaggtcctgggatgccattaatcg $3^{\prime}$ & $5^{\prime}$ tagtccaccattgccagattcacc $3^{\prime}$ \\
\hline
\end{tabular}

photericin $\mathrm{B}$ in a humidified atmosphere containing 5\% $\mathrm{CO}_{2}$ at $37^{\circ} \mathrm{C}$.

The HEK-293 cell line with stably over-expressed mouse B1R was generated as described earlier (Zubakova et al., 2007). Cells were cultured in high glucose DMEM medium supplemented with $10 \%$ fetal bovine serum and with an antibiotic/antimycotic mixture as described above. For binding experiments, cells were seeded in 96-well plates pre-treated with $0.01 \%$ solution of poly-lysine, and cultivated overnight to achieve $80-100 \%$ confluence in culture medium. The cells were then treated with $10 \mu \mathrm{g} / \mathrm{ml}$ tetracycline in the medium for one day more to enrich the B1R expression at the cell surface.

Gene expression analysis. The total RNA of untreated cells or cells incubated with $10 \mathrm{ng} / \mathrm{ml}$ TNF- $\alpha$ for several hours was isolated with Total RNA Isolation kit (Promega, USA). mRNA expression for B1R, B2R, CPM, hK1, kininogen, PPK, PRCP was analyzed with a two step RT-PCR procedure. The amount of elongation factor 2 (eEF2K) mRNA was also determined in each sample for the subsequent semiquantitative analysis. After mRNA transcription with M-MLVReverse Transcriptase kit (Promega, USA), amplification of cDNA $(2 \mu \mathrm{l})$ was performed in a $25 \mu$ l reaction mixture with the Taq polymerase kit (Finnzymes, Finland), $0.1 \mathrm{mM}$ dNTP (Fermentas, Canada) and $0.2 \mu \mathrm{M}$ specific primers in a MJ Mini Personal Thermal cycler (BioRad Laboratories, USA). The primer pair sequences for the analyzed genes were obtained from Genomed (Poland) and are specified in Table 1. The annealing temperature for PCR reaction was $58^{\circ} \mathrm{C}$, except for $\mathrm{hK} 1\left(68^{\circ} \mathrm{C}\right)$. The thermal cycler conditions were: $95^{\circ} \mathrm{C}$ for $5 \mathrm{~min}$, followed by $95^{\circ} \mathrm{C}$ for $30 \mathrm{~s}, 30 \mathrm{~s}$ at the corresponding annealing temperature, $72^{\circ} \mathrm{C}$ for 30 $\mathrm{s}$ (35 cycles) and $10 \mathrm{~min}$ at $72^{\circ} \mathrm{C}$. The PCR products for B1R, B2R, CPM, kininogen, hK1, PPK, PRCP and eEF-2K, resolved in $2 \%$ agarose gels, were $65 \mathrm{bp}, 141$ bp, 715 bp, 233 bp, 151 bp, 141 bp, 160 bp, and 218 bp long, respectively. For semiquantitative analysis, the gel-band intensity of the PCR products was measured by densitometry with the Fluor-S MultiImager (BioRad) and Quantity One software. The relative expression of genes was calculated as the ratio of the intensity of the analyzed PCR product band to the intensity of the eEF-2K PCR product band in each analyzed sample. The results are presented as the relative mRNA expression of the studied gene in response to TNF- $\alpha$ stimulation. The relative mRNA expression in non-stimulated cells was assumed to equal 1 .

Kininogen binding on cell surface. HK was labeled with fluorescein according to the manufacturer's procedure. After dialysis and protein determination, the labeled kininogen (Fl-HK) was used for the cell binding study. Detached cells $\left(0.5 \times 10^{6}\right)$ were suspended in $50 \mu \mathrm{l}$ of solution of Fl-HK in Tyrode's buffer supplemented with $50 \mu \mathrm{M} \mathrm{ZnCl}$. The Fl-HK concentration ranged from 1.56 to 150 nM. Control samples without the labeled kininogen were also prepared. After 1-h incubation, the cells were separated from unbound Fl-HK, gently washed with the binding buffer and the fluorescence intensity of bound $\mathrm{HK}$ was analyzed with a Flow Cytom- 
eter LSRII (Becton Dickinson, USA) at $\lambda_{\mathrm{ex}}=488$ $\mathrm{nm}$ and $\lambda_{\mathrm{em}}=530 \mathrm{~nm}$.

Detection of kininogen degradation by Western blotting. Cells $\left(3.0 \times 10^{6}\right)$ were incubated with $10 \mathrm{ng} /$ $\mathrm{ml} \mathrm{TNF}-\alpha$ at $37^{\circ} \mathrm{C}$ for six hours in the culture medium. After incubation, cells were washed and 100 nM HK was added, followed by incubation for 1-2 hours at $37^{\circ} \mathrm{C}$. Then, the supernatants were separated from cells and prepared for electrophoretic analysis of HK degradation. Equal volumes of each sample (15 $\mu \mathrm{l}$ ) were subjected to SDS/PAGE (Laemmli system, $10 \%$ gel), and the resolved polypeptides were transferred to polyvinylidene difluoride membranes (Sigma) in $10 \mathrm{mM}$ CAPS buffer, $\mathrm{pH} 10.0$ for $1 \mathrm{~h}$. After an overnight blocking with $5 \%$ nonfat milk, the membrane was incubated for $1 \mathrm{~h}$ at room temperature with mouse specific primary antibodies to human $\mathrm{HK}$ heavy and light chains at 1:1000 dilution. Next, after extensive washing, the membrane was incubated with the respective secondary antibody conjugated with alkaline phosphatase at 1:2000 dilution. After one hour incubation and extensive washing, the enzymatic reaction with Fast BCIP/NBT was performed according to the manufacturer's instructions.

Measurement of kinin and des-Arg kinin production. Cells $\left(3.0 \times 10^{6}\right)$ were incubated with $10 \mathrm{ng} /$ $\mathrm{ml} \mathrm{TNF}-\alpha$ in MEM medium at $37^{\circ} \mathrm{C}$ for $6 \mathrm{~h}$. After centrifugation, the supernatant was removed and the cells were incubated with $100 \mathrm{nM}$ HK in $100 \mu \mathrm{l}$ Ty-

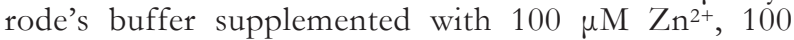
$\mu \mathrm{M}$ captopril and $500 \mu \mathrm{M}$ bacitracin for up to $30 \mathrm{~min}$ at $37^{\circ} \mathrm{C}$. After incubation, the samples were immediately placed in an ice bath and the supernatants were separated from cells by centrifugation, 5-fold diluted and immediately analyzed for kinin or des-Arg-kinin contents. Similar experiments, with the incubation of cells with $1 \mu \mathrm{M} \mathrm{KD}$, were also performed. The kinins were determined with the Bradykinin EIA Kit (Peninsula, Germany) following the manufacturer's instructions. The concentration of des-Arg kinins was measured using a competitive radiocompetitive receptorbinding assay with B1R-overexpressing HEK-293 cells as previously described (Guevara-Lora et al., 2011).

Determination of carboxypeptidase activity. Analysis of the carboxypeptidase activity in U-373 cells was performed by the measurement of enzymatic degradation of the labeled DAA peptide (Tan et al., 1992). The procedure was optimized for the present study. For this purpose, $2 \times 10^{6}$ cells after 6 -h incubation with $10 \mathrm{ng} / \mathrm{ml} \mathrm{TNF}-\alpha$ were lysed by a mild sonication in PBS supplemented with protease inhibitor cocktail. Next, $50 \mu \mathrm{l}$ of lysates were incubated with $0.2 \mathrm{mM}$ DAA in $0.1 \mathrm{M}$ Hepes buffer, $\mathrm{pH} 7.0$, supplemented with $0.2 \%$ Triton $\mathrm{X}-100$ for 2 hours at $37^{\circ} \mathrm{C}$. The enzymatic reaction was stopped by the addition of $150 \mu \mathrm{l}$ of $1 \mathrm{M}$ citric acid. The obtained product was extracted through the addition of $1 \mathrm{ml}$ chloroform with vigorous vortexing. After centrifugation (10 $\min , 1000 \times \mathrm{g}$ ), the fluorescence of the organic phase was measured using a F-4500 fluorescence spectrophotometer (Hitachi, Japan). Negative control samples (samples without cell lysate or samples with cell lysate but without DAA) as well as the samples in which the enzymatic activity was inhibited with $10 \mu \mathrm{M}$ MGTA for $10 \mathrm{~min}$ before the incubation with substrate, were also prepared. The relative carboxypeptidase activity was presented as the difference of fluorescence intensity between samples measured without or in the presence of $10 \mu \mathrm{M}$ MGTA after 2-h incubation with substrate.

\section{RESULTS AND DISSCUSION}

\section{Expression of the components of kinin-generating systems in glioblastoma cell line U-373}

The abundance of kinin-generating proteins has been studied in diverse tissues confirming the presence of all the components necessary to produce these peptides in different types of cells (Blais et al., 2000; Fernando et al., 2003; Joseph \& Kaplan, 2005). The best studied system of cell surface-mediated kinin production is that of endothelial cells but the activation of kinin-forming systems on other cells, including those involved in inflammatory processes was the subject of numerous studies (Barbasz \& Kozik, 2009; Varano et al., 2011; Guevara-Lora et al., 2011). The close relationship between inflammation and cancer has rationalized the investigation of the kinin role in processes associated with tumour formation and propagation (Maeda et al., 1999; Figueroa et al., 2012). In the current study, we analyzed the expression of the components of the kinin-generating system by the hu-

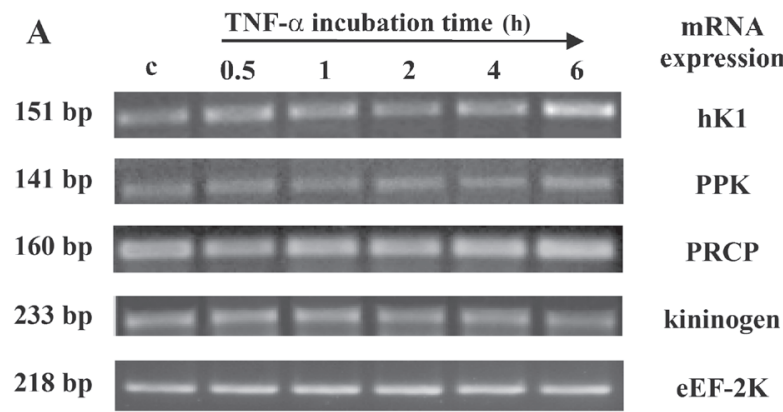

B

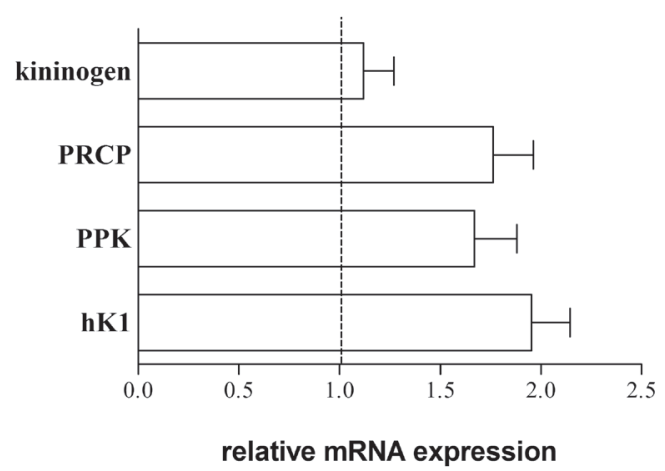

Figure 1. Expression of proteins involved in kinin generation in U-373 cells stimulated with TNF-a

Cells $\left(3 \times 10^{6}\right)$ were incubated with $10 \mathrm{ng} / \mathrm{ml}$ TNF-a at different time intervals $(0.5,1,2,4$ and 6 hours) and the mRNA expression for hK1, PPK, PRCP, kininogen and eEF-2K was analyzed by twostep RT-PCR. The obtained PCR products were separated in $2 \%$ agarose gel (A). Semi-quantitative analysis of RT-PCR was performed by measuring the gel-band intensity of PCR products by densitometry. For each sample the intensity of the PCR product band at the time of maximal expression ( $6 \mathrm{~h}$ ) was divided by the intensity of eEF-2K PCR product band and the ratio was compared to that of untreated cells assumed to equal 1 (B). The values represent means \pm S.D. from at least three experiments. 


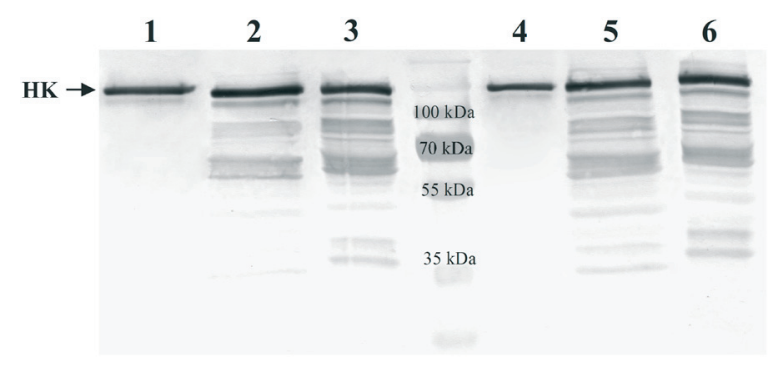

Figure 2. Kininogen degradation by human glioblastoma cells HK $(100 \mathrm{nM})$ was incubated alone (lanes 1,4$)$ or with cells $\left(3 \times 10^{6}\right)$ without stimulation (lanes 2,5) and after stimulation with $10 \mathrm{ng} /$ $\mathrm{ml}$ TNF-a (lanes 3, 6) for $1 \mathrm{~h}$ (lanes $1-3$ ) or for $2 \mathrm{~h}(4-6)$. The obtained products of HK degradation were selectively detected by Western blotting with specific antibodies against peptides with sequences belonging to the heavy and light chains of kininogen.

man glioblastoma cell line U-373, derived from a malignant tumor. Our results demonstrated that enzymes involved in the kinin generation, such as hK1, PPK and PRCP were present in cells at least at the mRNA level (Fig. 1). Moreover, expression of these enzymes could be induced by cytokines, such as TNF- $\alpha$ (Fig. 1). The relative expression for $h K 1, P P K$ and PRCP mRNA was considerably enhanced after 6-hour incubation with TNF- $\alpha$. The expression of hK1 in our model cells was to be expected. The expression of tissue kallikreins in tumors is unquestionable and some of these proteins are considered specific markers of carcinogenesis owing to their involvement in tumor metastasis and invasion (Borgono et al., 2004, Obiezu \& Diamandis, 2005; Chee et al., 2008). A more interesting observation is the appearance of PPK expression in U-373 cells. In an earlier study, we demonstrated a minor expression of this kininogenase in neuroblastoma cell line IMR-32, suggesting a possibility of activation of the contact system by these cells (Guevara-Lora et al., 2011). Like in that previous study, in the current work we also observed a slight increase in PPK expression in the presence of cytokines (by ca. 60\%) (Fig. 1B). The probability that the contact system may be activated in U-373 cells is high, because these cells exhibited also a strong expression of PRCP that was additionally enhanced by TNF- $\alpha$ (by $70 \%$ ).

Despite the fact that expression of these enzymes was observed at the mRNA level, the results obtained from the incubation of exogenous HK with U-373 cells suggested their presence on the cell surface. Kinino- gen degradation after incubation with glioblastoma cells was studied by Western blotting with specific antibodies against $\mathrm{HK}$ chains (Fig. 2). Degradation of $\mathrm{HK}$, visible already after 1 -h incubation, was greater after one additional hour (lanes 2 and 5, respectively). Moreover, HK degradation was enhanced when cells were pre-treated with TNF- $\alpha$ (lanes 3 and 6 , respectively). In each case, bands with molecular weights close to those expected for HK degradation by kallikreins were observed (Colman \& Schmaier, 1997). However, the action of other proteinases cannot be excluded because longer incubation of $\mathrm{HK}$ with cells led to extensive degradation with generation of protein bands with apparent molecular weights as low as about $35 \mathrm{kDa}$. Control samples containing HK without cells did not show protein degradation after 1 - or 2 -h incubation (lanes 1 and 4, respectively).

An important finding of the current work was the detection of kininogen $\mathrm{mRNA}$ in glioblastoma cell line U-373 (Fig. 1A). Although there were no evident changes in the mRNA level after cytokine stimulation, these cells may be a source of kininogen production in nervous tissues, especially since a relatively high concentration of HK was reported in the cerebrospinal fluid (Scicli et al., 1984).

\section{Release of kinins and kinin-like peptides genered from exogenous kininogen by U-373 cells}

Activation of the contact system requires kininogen binding to the cell surface. We analyzed the binding of fluorescein-labeled HK to glioblastoma cells by flow cytometry. Representative plots for this interaction are shown in Fig. 3. The percentage of cells bearing the bound protein was comparable regardless of the number of cells incubated with Fl-HK (Fig. 3A). The plots of the fluorescence intensity of bound Fl-HK versus the total concentration of labeled kininogen added (the "saturation binding" plots) are presented in Fig. 3B. These plots were numerically analyzed for the estimation of the apparent dissociation constant with the GraphPad Prism software. Although the saturation binding plots were different depending on the amount of cells taken for the analysis, the calculated dissociation constants were comparable, with a mean value of $9.2 \pm 1.4 \mathrm{nM}$. These results are in agreement with an earlier study in which a strong HK binding at the surface of astrocytes was demonstrated (Fernando et al., 2003).

The demonstration of HK binding to cells allowed us to hypothesize that the contact system can be triggered on cell surface to release kinins, probably mainly BK.
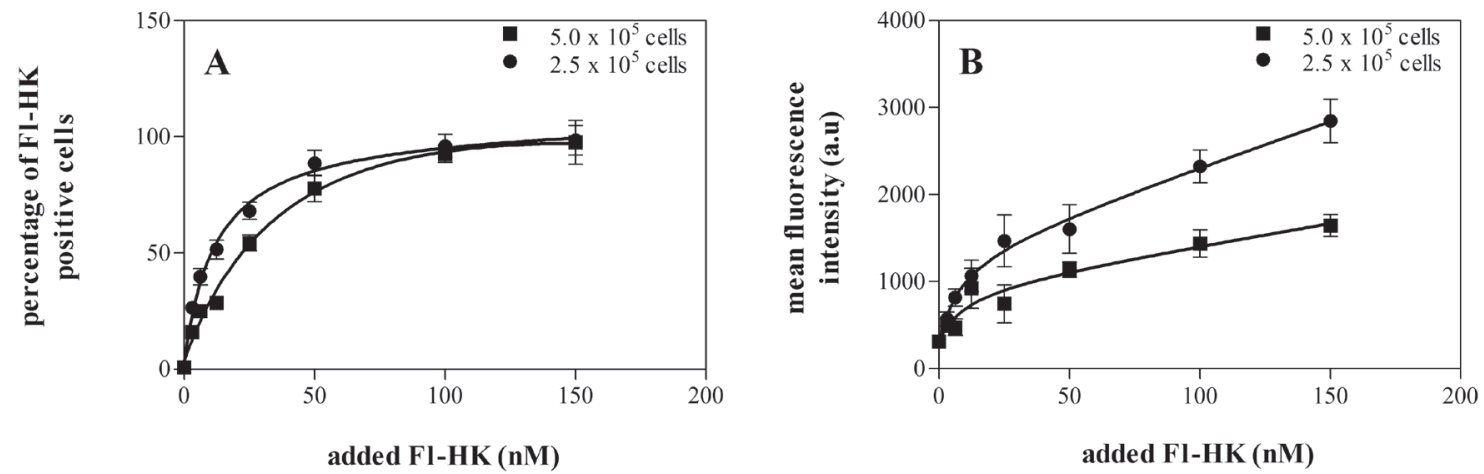

Figure 3. Binding of fluorescein-labeled HK to U-373 cells

Cells were incubated with Fl-HK at the concentration of up to $150 \mathrm{nM}$, for $1 \mathrm{~h}$ at $37^{\circ} \mathrm{C}$. The percentage of cells with bound FI-HK (A) and the mean fluorescence intensity from bound Fl-HK (B) were measured by flow cytometry. The results represent the mean \pm S.D. from at least three experiments. 

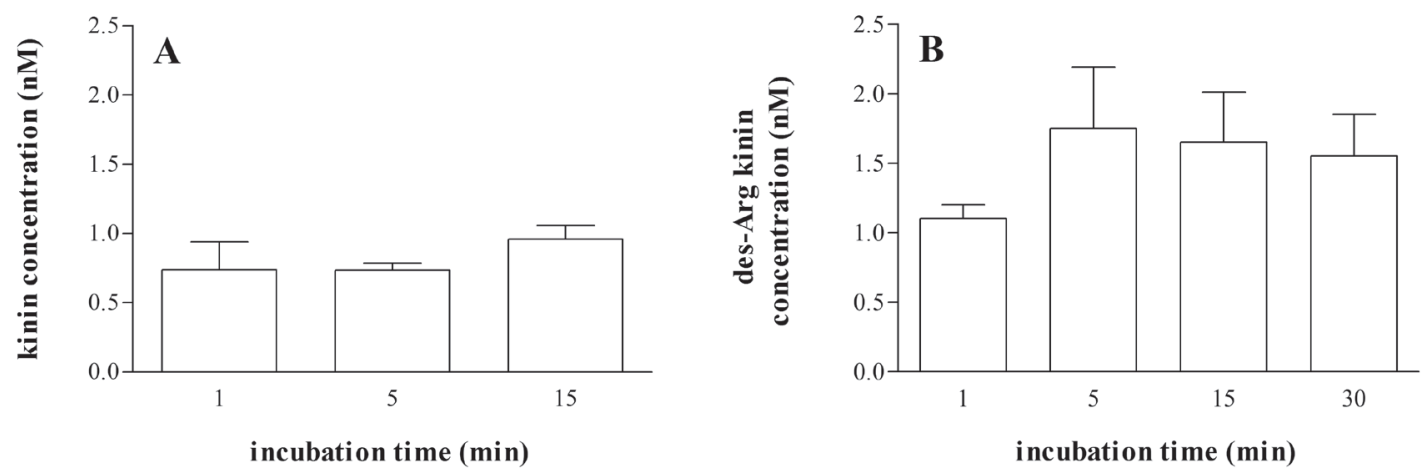

Figure 4. Kinin and des-Arg kinin generation from exogenous HK by TNF-a-stimulated human glioblastoma cells Cells $\left(3.0 \times 10^{6}\right)$ were stimulated with $10 \mathrm{ng} / \mathrm{ml}$ TNF-a for 6 hours. After stimulation, cells were incubated with $100 \mathrm{nM} H \mathrm{HK}$ at $37^{\circ} \mathrm{C}$ for 1,5 , 15 and $30 \mathrm{~min}$, and the production of kinins (A) and des-Arg kinins (B) was determined by ElA and a radiocompetitive receptor-binding assay, respectively. The values represent means \pm S.D. from at least three experiments.

Our study showed kinin generation from exogeneous HK by cells pre-treated with TNF- $\alpha$. The incubation of cells with $100 \mathrm{nM} \mathrm{HK}$ resulted in a moderate production of kinins which were measured using the EIA assay (Fig. 4A). A comparable concentration of kinins was observed after different incubation times, ranging from 1 to $15 \mathrm{~min}$ (up to $1 \mathrm{nM}$ ). After $30 \mathrm{~min}$, no kinins could be detected. The yield of kininogen degradation (relatively to the total HK concentration added to cells) was low (about 1\%). Nevertheless, since the kinin stationary levels result from a dynamic balance of kinin generation and degradation by peptidases (kininases), the presence of other peptides, such as des-Arg kinins should be considered.

Hence, simultaneously to the kinin concentration measurements, the generation of their metabolites, the des-Arg kinins, was also analyzed. To determine their concentration, a radioligand receptor-binding assay was applied. The production of des-Arg kinins reached a maximum after 5-min $\mathrm{HK}$ incubation with the cells (up to $2 \mathrm{nM}$ ) and slightly decreased with the increasing incubation time (Fig. 4B). A higher concentration of these peptides as compared to that of full-length kinins in the same samples can be explained by different half-lives of both types of peptides (Blais et al, 2000). Different degradation kinetics may lead to des-Arg kinin accumulation and promote chronic inflammatory processes. In tumor tissues, this fact may be of primordial importance ow- ing to the pro-adhesive and chemotactic properties of these peptides (McLean et al., 2000; Guevara-Lora et al., 2011). Leukocytes possess multiple roles in angiogenesis, as well as in tumor metastasis and invasion (Lee et al., 2013). Therefore, the presence of des-Arg kinins may promote cancer through B1 receptors as has been suggested recently (Molina et al., 2009).

The use of a potent inhibitor of carboxypeptidase activity, MGTA, abolished the generation of des-Arg kinins from exogenous HK. The expression of CPM, the cell membrane-bound kininase responsible for the removal of the arginine residue from the kinin C-terminus, was analyzed by RT-PCR but no evidence of the expression of this enzyme at the mRNA level was observed (results not shown). Instead, determination of DAKD production from exogenous $\mathrm{KD}$ using a radiocompetitive receptor-binding assay has shown a remarkable carboxypeptidase activity in glioblastoma U-373 cells (Fig. 5A). The cytokine pre-treated cells were able to degrade $1 \mu \mathrm{M}$ $\mathrm{KD}$ quickly and effectively. After 5-min incubation with $\mathrm{KD}$, the generated des-Arg kinin achieved the maximal concentration (up to $8 \mathrm{nM}$ ) that dropped by only $25 \%$ after $30 \mathrm{~min}$. In the presence of $1 \mu \mathrm{M}$ MGTA, the cells failed to generate DAKD. The ability of U-373 cells to remove C-terminal Arg residues was also tested by the measurements of $1 \mathrm{mM}$ DAA degradation (Fig. 5B). The relative enzymatic activity of lysates obtained before and after TNF- $\alpha$ treatment for 3 hours demonstrated a

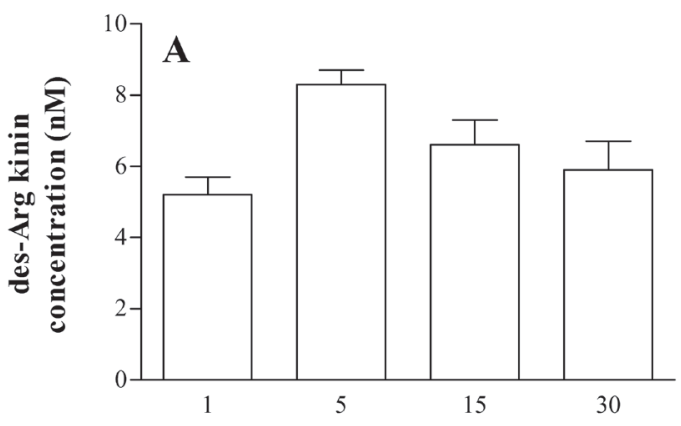

incubation time (min)

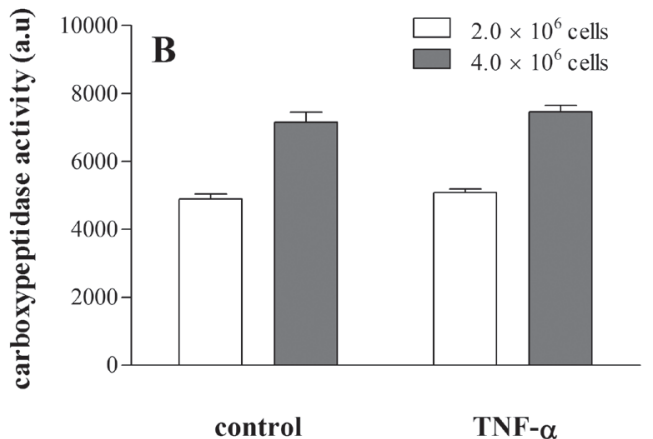

Figure 5. Carboxypeptidase activity of the human glioblastoma cell line U-373

The production of des-Arg kinins by cells $\left(3.0 \times 10^{6}\right)$ pre-treated with $10 \mathrm{ng} / \mathrm{ml}$ TNF-a were determined after incubation with $1 \mu \mathrm{M}$ KD at $37^{\circ} \mathrm{C}$ for $1,5,15$ and $30 \mathrm{~min}$. The des-Arg kinin concentration was measured by a radiocompetitive receptor-binding assay $(\mathbf{A})$. The enzymatic activity of carboxypeptidases in untreated or TNF-a-stimulated cells was measured with 1 mM DAA for 2 hours. The relative enzymatic activity, calculated as the change of fluorescence intensity between samples incubated with $10 \mu \mathrm{M}$ MGTA and untreated with the inhibitor was presented for non-stimulated or $10 \mathrm{ng} / \mathrm{ml} \mathrm{TNF-a} \mathrm{stimulated} \mathrm{cells} \mathrm{(B).} \mathrm{The} \mathrm{values} \mathrm{represent} \mathrm{means} \pm S$.D. from at least three experiments. 


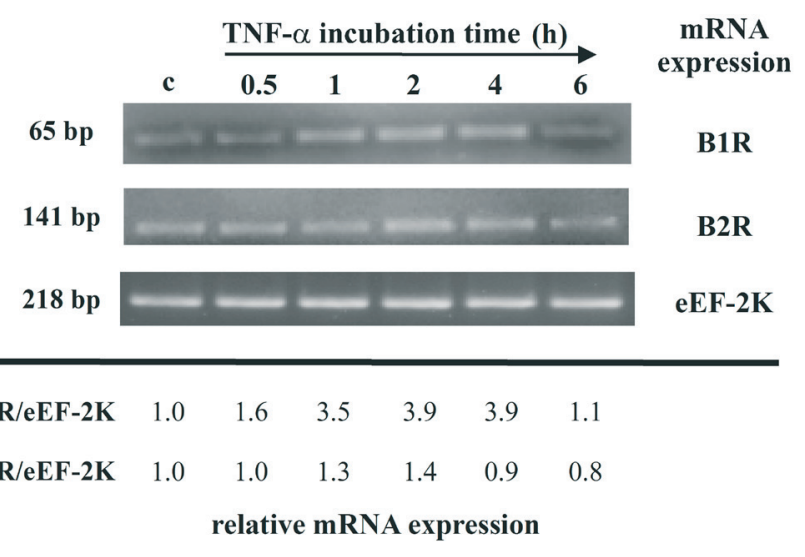

Figure 6. Kinin receptor expression in U-373 cells after TNF-a stimulation Cells $\left(3 \times 10^{6}\right)$ were incubated with $10 \mathrm{ng} / \mathrm{ml}$ TNF- $\alpha$ at different time intervals $(0.5,1,2,4$ and 6 hours) and the mRNA expression for B1R, B2R and eEF-2K was analyzed by two-step RT-PCR. The obtained PCR products were separated in $2 \%$ agarose gel and densitometric analysis of band intensity was performed. The ratio of mRNA expression for a given gene and eEF$2 \mathrm{~K}$ was calculated for each time of incubation with TNF-a and compared to the ratio for untreated cells that was assumed to equal 1 . The data points represent means from at least three experiments.

high propensity of these cells to produce des-Arg kinins. An enhancement of carboxypeptidase activity was observed with an increasing in cell number while TNF- $\alpha$ pretreatment did not significantly affect the enzymatic degradation of DAA. These results sufficiently support the hypothesis on the participation of carboxypeptidases in kinin degradation in the system studied. Although we failed to detect CPM mRNA in U-373 cells, other researchers did confirm expression of this enzyme in the brain (Nagae et al., 1992). Moreover, it seems that other carboxypeptidases, such as carboxypeptidase E whose expression in glioblastoma cells was confirmed, can play a role in the formation of B1R agonists (Lynch et al., 1990). Interestingly elevated expression of this carboxypeptidase correlates with tumor growth and metastasis in cancer (Murthy et al., 2010).

\section{Expression of kinin receptors in glioblastoma cells after TNF-a stimulation}

Given the above results, we examined the expression of kinin receptors in this cell model and the influence of TNF- $\alpha$ on this expression. The ratio of B1R or B2R mRNA expression to that of eEF-2K was calculated and the relative change in gene expression after TNF- $\alpha$ stimulation was estimed in comparision with untreated cells. Both B1R and B2R were expressed at mRNA level; however, B2R expression was higher as compared to B1R (Fig. 6). Our results are consistent with other studies in which both subtypes of kinin receptors in tumor tissues have been detected (Maeda et al., 1999; Wu et al., 2002; Molina et al., 2009; Toledo et al., 2012). The current finding that TNF- $\alpha$ influences kinin receptor expression is more original. Essential changes of kinin receptor expression after cytokine treatment were observed in the studied cellular model. The increase in B2R expression was moderate, with the maximal cytokine effect after $2 \mathrm{~h}$ incubation (40\% increase) whereas B1R expression was much more strongly influenced by TNF- $\alpha$ (300\% increase). In the case of B1R, TNF- $\alpha$ stimulated cells showed a fast (B1R expression increased by $60 \%$ already after 30-min incubation) and an extended (increased expression was preserved up to 5 hours) effect.
Such a difference in the expression of kinin receptors caused by pro-inflammatory cytokines may prove relevant to studies related to cancer treatment with antagonists that have gained in importance in recent years (Sharma \& Al-Sherif, 2011; Figueroa et al., 2012).

The results obtained in this work suggest that the selection of a cell model to study anticancer therapies is worth to be reconsidered. For example, the new approaches in glioblastoma treatment are associated with therapies which target the extracellular matrix and receptors, growth factors and cytokines, proteases, cytoskeletal components, oncogenes and tumor suppressor genes (Tysnes \& Mahesparan, 2001). The elaboration of appropriate and representative in vitro experimental systems is of pivotal importance for the characterization of processes involved in cancer cell invasion, especially at the molecular level. In our study we showed for the first time that tumor cells can produce kinins after cytokine stimulation. The kinins, in turn, can be converted into more stable peptides, the desArg kinins, leading to an increase in the active peptide concentration in cancer tissues. Hence, this cell model offers new perspectives for anticancer therapies and facilitates the search for new molecules that can be potential targets in therapies directed at inhibiting cell migration. Numerous studies have demonstrated that BR2 is a good candidate for anticancer treatment (Jutras et al., 2010; Montana et al., 2011) but we suggest that B1R can be even a better target for anti-invasive therapy, because it is highly expressed in response to inflammatory stimuli it. In a recent report, this receptor was shown to mediate glioma cell migration $(\mathrm{Lu}$ et al., 2010). Additionally, as suggested by our results, molecules involved in the production of kinin peptides, such as PRCP, kallikreins or carboxypeptidases can be promising candidates for the inhibition of cancer invasion. The use of specific inhibitors of these enzymes can offer new perspectives on cancer treatment.

Concluding, in the current study we report the ability of kinin generation by cells derived from human glioblastoma. The probability that activation of the contact system is responsible for kinin release is high but the involvement of tissue kallikrein in this process cannot be excluded. These observations provide important data on the control of kinin effects in cancer tissues, which can be potentially useful for therapeutic purposes. In particular, our results suggest that not only the blocking of kinin receptors but also inhibition of the production of kinins and their des-Arg metabolites should be taken into consideration. Finally, the kinin effects can vary depending on the stage of tumor development. We believe that the cellular model hereby analyzed can be useful for cancer treatment studies.

\section{REFERENCES}

Barbasz A, Kozik A (2009) The assembly and activation of the kininforming systems on the surface of human U-937 macrophage-like cells. Biol Chem 390: 269-275.

Bhoola KD, Figueroa CD, Worthy K (1992) Bioregulations of kinins: Kallikreins, kininogens and kininases. Pharmacol Rev 44: 1-80.

Blais C, Marceau F, Rouleau J-L, Adam A (2000) The kallikrein-kininogen-kinin system: lessons from the quantification of endogenous kinins. Peptides 21: 1903-1940.

Borgoño CA, Michael IP, Diamandis EP (2004) Human tissue kallikreins: physiologic roles and applications in cancer. Mol Cancer Res 2: $257-280$. 
Chee J, Naran A, Misso NL, Thompson PJ, Bhoola KD (2008) Expression of tissue and plasma kallikreins and kinin B1 and B2 receptors in lung cancer. Biol Chem 389: 1225-1233.

Colman RW, Schaimer AH (1997) Contact system. A vascular biology modulator with anticoagulant, profibrinolytic, antiadhesive, and proinflammatory attributes. Blood 90: 3819-3843.

Dean RL, Emerich DF, Hasler BP, Bartus RT (1999) Cereport ${ }^{\circledR}$ (RMP-7) increases carboplatin levels in brain tumors after pretreatment with dexamethasone. Neuro Oncol 1: 268-274.

Fernando L, Natesan S, Joseph K, Kaplan AP (2003) High molecular weight kininogen and factor XII binding to endothelial cells and astrocytes. Thromb Haemost 90: 787-795.

Figueroa CD, Ehrenfeld P, Bhoola KD (2012) Kinin receptors as targets for cancer therapy. Exp Op Ther Targets 16: 299-312.

Finger EC, Giaccia JA (2010) Hypoxia, inflammation, and the tumor microenvironment in metastatic disease. Cancer Metastasis Rev 29: 285-293.

Geiger TR, Peeper DS (2009) Metastasis mechanisms. Biochim Biophys Acta 1796: 293-308.

Guevara-Lora I, Labedz A, Skrzeczynska-Moncznik J, Kozik A (2011) Bradykinin and des-Arg ${ }^{10}$-kallidin enhance the adhesion of polymorphonuclear leukocytes to extracellular matrix proteins and endothelial cells. Cell Comm Adh 18: 67-71.

Guevara-Lora I, Majkucinska M, Barbasz A, Faussner A, Kozik A (2011) Kinin generation from exogenous kininogens at the surface of retinoic acid-differentiated human neuroblastoma IMR-32 cells after stimulation with interferon- $\gamma$. Peptides 32: 1193-1200.

Joseph K, Kaplan AP (2005) Formation of bradykinin: a major contribution to the innate inflammatory response. Adv Immunol 86: 159-208.

Jutras S, Bachvarova M, Keita M, Bascands JL, Mes-Masson AM, Stewart JM, Gera L, Bachvarov D (2010) Strong cytotoxic effect of the bradykinin antagonist BKM-570 in ovarian cancer cells analysis of the molecular mechanisms of its antiproliferative action. FEBS I 277: 5146-5160.

Lee H-W, Choi H-J, Ha S-J, Lee K-T, Kwon Y-G (2013) Recruitment of monocytes/macrophages in different tumor microenvironments. Biochim Biophys Acta 1835: 170-179.

Leeb-Lundberg LMF, Marceau F, Muller-Esterl W, Pettibone DJ, Zuraw BL (2005) International union of pharmacology. XLV. Classification of the kinin receptor family: from molecular mechanism to pathophysiological consequences. Pharmacol Rev 57: 27-77.

Liu L, Xue Y, Liu Y (2010) Bradykinin increases the permeability of the blood-tumor barrier by the caveolae-mediated transcellular pathway. J Neurooncol 99: 187-194.

López-Valdés HE, Beltran-Parraza L, Brennan KC, Charles AC (2010) Bradykinin increases resensitization of purinergic receptor signaling in glioma cells. Cancer Cell Int 10: 35-43.

Lu D-Y, Leung Y-M, Huang S-M, Wong K-L (2010) Bradykinin-induced cell migration and COX-2 production mediated by the bradykinin B1 receptor in glioma cells. J Cell Biochem 110: 151-150.
Lynch DR, Braas KM, Hutton JC, Snyder SH (1990) Carboxypeptidase $\mathrm{E}$ (CPE): lmmunocytochemical localization in the rat central nervous system and pituitary gland. J Neurosc 10: 1592-1 599.

Maeda H, Wu J, Okamoto T, Maruo K, Akaike T (1999) Kallikreinkinin in infection and cancer. Immunopharmacology 43: 115-128.

McLean PG, Ahluwalia A, Perretti M (2000) Association between kinin B1 receptor expression and leukocyte trafficking across mouse mesenteric postcapillary venules. I Exp Med 192: 367-380.

Molina L, Matus CE, Astroza A., Pavicic F, Tapia E, Toledo C, Perez J, Nualart F, Gonzalez CB, Burgos R, Figueroa CD, Ehrenfeld P, Poblete MT (2009) Stimulation of the bradykinin B1 receptor induces the proliferation of estrogen-sensitive breast cancer cells and activates the ERK1/2 signaling pathway. Breast Cancer Res Treat 118: $499-510$.

Montana V, Sontheimer H (2011) Bradykinin promotes the chemotactic invasion of primary brain tumors. J Neurosci 31: 4858-4867.

Murthy SRK, Pacak K, Peng Loh Y (2010) Carboxypeptidase E: Elevated expression correlated with tumor growth and metastasis in pheochromocytomas and other cancers. Cell Mol Neurobiol 30: 13771381.

Nagae A, Deddish PA, Becker RP, Anderson CH, Abe M, Tan F, Skidgel RA, Erdös EG (1992) Carboxypeptidase M in brain and peripheral nerves. J Neurochem 59: 2201-2212.

Obiezua CV, Diamandis EP (2005) Human tissue kallikrein gene family: applications in cancer. Cancer Letters 224: 1-22.

Scicli AG, Forbes G, Nolly H, Dujovny M, Carretero OA (1984) Kallikrein-kinins in the central nervous system. Clin Exp Hypertens $A \mathbf{6}$ : 1731-1738.

Sharma JN, Al-Sherif GJ (2011) The Kinin System: Present and future pharmacological targets. Am J Biomed Sci 3: 156-169.

Tan F, Deddish P A, Skidgel RA (1992) Human carboxypeptidase M. Methods Enzymol 248: 663-675.

Toledo C, Matus CE, Barraza X, Arroyo P, Ehrenfeld P, Figueroa CD, Bhoola KD, del Pozo M, Poblete MT (2012) Expression of HER2 and bradykinin $\mathrm{B}$ receptors in precursor lesions of gallbladder carcinoma. World J Gastroenterol 18: 1208-1215.

Tysnes BB, Mahesparan R (2001) Biological mechanisms of glioma invasion and potential therapeutic targets. I Neuro-Oncol 53: 129-147.

Varano de la Vergiliana JF, Lansley S, Tan AL, Creaney J, Lee YC, Stewart GA (2011) Mesothelial cells activate the plasma kallikreinkinin system during pleural inflammation. Biol Chem 392: 633-642.

Wu J, Akaike T, Hayashida K, Miyamoto Y, Nakagawa T, Miyakawa K, Muller-Esterl W, Maeda H (2002) Identification of bradykinin receptors in clinical cancer specimens and murine tumor tissues. Int J Cancer 98: 29-35.

Zubakova R, Gille A, Faussner A, Hilgenfeldt U (2007) $\mathrm{Ca}^{2+}$ signaling of kinins in cells expressing rat, mouse and human $\mathrm{B}_{1} / \mathrm{B}_{2}$-receptor. Int Immunopharm 8: 276-281. 
